\title{
Food Product Stability Duration
}

National Cancer Institute

\section{Source}

National Cancer Institute. Food Product Stability Duration. NCI Thesaurus. Code C95365.

The period of time during which the food product is considered stable. 